\title{
Pedagogical Content Knowledge of Science Tutors and Its Influence on Their Trainees
}

\author{
Moses Abdullai Abukari ${ }^{1}$ (), Jonas Bayuo ${ }^{1 *}$ (i), Alaric Awingura Alagbela ${ }^{1}$ (i), Christopher Saaha Bornaa $^{2}$ (1)
}

${ }^{1}$ Department of Science Education, C. K. Tedam University of Technology and Applied Sciences, Navrongo, Upper East Region, GHANA

${ }^{2}$ Department of Mathematics and ICT Education, C. K. Tedam University of Technology and Applied Sciences, Navrongo, Upper East Region, GHANA *Corresponding Author: jbayuo@cktutas.edu.gh

Citation: Abukari, M. A., Bayuo, J., Alagbela, A. A., \& Bornaa, C. S. (2022). Pedagogical Content Knowledge of Science Tutors and Its Influence on Their Trainees. Contemporary Mathematics and Science Education, 3(1), ep22008. https://doi.org/10.30935/conmaths /11830

\begin{abstract}
This study presents the pedagogical content knowledge of science tutors of colleges of education and its impact on the pedagogical content knowledge advancement of teacher trainees. A descriptive survey design was employed to obtain data for the study using 120 teacher trainees and six science tutors from two colleges of education. The research instruments used for the study were a questionnaire, interview guide, and observation checklist. The study found that the pedagogical content knowledge demonstrated by the science tutors was dependent on the number of years of teaching experience and qualification. Out of the six tutors, two tutors demonstrated the highest pedagogical content knowledge with 10-12 years of teaching experience. The Pearson's product-moment correlation coefficient ( $r$ ) was found to be reaching unity suggesting that the science tutors' pedagogical content knowledge has a very strong positive influence on their teacher trainees' pedagogical content knowledge development. About $62.5-87.5 \%$ of their pedagogical content was influenced by the pedagogical content knowledge of their tutors. Based on the findings, the study recommends adaptation of a transformative model of pedagogical content knowledge, for initial training of teacher trainees starting out as teachers and continuous training for experienced teachers who are learning to teach new subjects. This will offer a mechanism for changing practice.
\end{abstract}

Keywords: college, pedagogical content knowledge, science, teacher-trainee, tutor

Received: 22 Oct. $2021 \bullet$ Accepted: 21 Feb. 2022

\section{INTRODUCTION}

It is a notable fact that tutors' pedagogical content knowledge (PCK) will influence how teaching and learning are carried out in the classroom. It is conventionally accepted that for any effective teaching, the tutor should have both the content knowledge and the pedagogy. A tutor with deep PCK understands how teacher trainees construct knowledge and acquire skills and how they develop habits of mind and positive dispositions toward learning (Skedsmo, 2020). Adi Putra et al. (2017) explained PCK as the depiction and articulation of ideas, pedagogical strategies, knowledge of what makes principles difficult or simple to learn previous knowledge of students and epistemological theories.

The tutor's competency is an important aspect in teacher trainee behavior and learning, as well as pedagogical advancement and the acquisition of knowledge by the trainee. The components of PCK take into account what pedagogical knowledge is and the way tutors view their pedagogy. According to the PCK description by Alkis-Kucukaydin and Ulucinar Sagir (2016), it is essential to organize the tutor's content knowledge in line with the needs and interests of the teacher trainees. Alternative methods, such as analogy, illustration, and simulations, as well as knowledge transfer can be used to accomplish this.
To operate as a qualified teacher, a teacher must possess a variety of skills, including not only the curriculum knowledge but also knowing how to assist students in their learning. Teachers guide students on how to study and assist them in using learning models that promote social, academic, and personal development (Sothayapetch et al., 2013). This is comparable to Williams' (2003) results, according to which a tutor needs to place more emphasis on the interrelationship between the art of teaching and the science of teaching-pedagogy for teacher trainees to attain their full potential (Sothayapetch et al., 2013).

Several investigations on the existence, characteristics, and consequences of science teachers' PCK have yielded positive results (Bayram-Jacobs et al., 2019). The majority of constructivist research found that pedagogy was crucial for professional career growth, even if academic knowledge in science was the most important factor (Melo et al., 2020; Shulman, 1986).

Science teaching and learning frequently focus on memorization of concepts and content knowledge, and teachers, particularly potential and beginning teachers, often have insufficient PCK (Tobin et al., 1990). As a result, when teaching science, these novice teachers are scared of unexpected challenges (Zembal-Saul et al., 2002).

PCK development aids prospective teachers in making adjustments to their teachings and provides experienced teachers with the 
opportunity to engage in self-regulatory reflective practices (Kind, 2009). According to van Driel et al. (2014), PCK development necessitates the presence of certain components. It is important to note that teachers' PCK expands in personal and unique ways based on the subject matter they are teaching (Melo et al., 2020).

As PCK is considered the core of professional knowledge, its presence in teacher training and development is essential. Hence, there is a demand that the interplay between learning and teaching process, which are philosophically dependent on one another is examined from several domains of pedagogical knowledge (Kind, 2009; Melo et al., 2020). However, characterizing PCK is a challenging task in the context of teaching science in schools and if PCK is to be added to teacher preparation programmes, it will necessitate further documentation and investigation. Thus, in pre-service and in-service teacher programmes, there is a lack of information regarding how to develop pedagogical content knowledge. To overcome this limitation, attempts should be accompanied by a thorough examination of classroom practices based on PCK domains. Therefore, this study investigates the PCK of science tutors of colleges of education in Ghana and their teacher trainees' PCK development.

\section{Statement of Problem}

Since the establishment of PCK in science education in the mid1980s, it has gotten a lot of scholarly attention, although many science teachers are unaware of it. Recently, educational leaders have expressed worry over the recurring substandard science performance by school children in examinations both internally and externally. Education stakeholders have expressed their dissatisfaction with the current situation and voiced concerns about how teacher trainees are being trained by tutors at the colleges of education in Ghana. It is expected that those teacher trainees who have been taught the curriculum content and methodology of teaching in the colleges and having gone through on- and off-campus teaching practices should be well-equipped to teach their students how to achieve academically. However, the case in our basic schools is different. Hence, there is the need to adopt a transformative PCK model to train teacher trainees to take up the challenges teaching offers.

The reasons why PCK should be a requirement and a general feature in pre-service teacher training programs include; it helps one to determine and deal with the variables that constitute and control the stability of instructional methods; verify the theoretical concepts that are imparted; appreciate how to examine the knowledge that teachers construct during their professional exposure; and reroute the connection between research and school practices (Etkina, 2010; Goes et al., 2020; Kind, 2009; Sperandeo-Mineo et al., 2006; Thompson et al., 2011). Therefore, this study seeks to find out the extent to which science tutors' PCK affects the PCK development of their teacher trainees in Ghana.

\section{Purpose of the Study}

The study seeks to investigate the PCK of science tutors in colleges of education and its influence on the PCK development of their teacher trainees.

\section{Research Questions}

The study sought to answer the following research questions.

1. What is the extent of PCK exhibited by science tutors of the colleges of education and their teacher trainees?
2. To what extent does the PCK of science tutors of colleges of education influence the PCK development of their teacher trainees?

3. Is there a relationship between teacher trainees' PCK and that of the PCK exhibited by their science tutors?

\section{Conceptual Framework}

This study adopted Park and Chen (2012) pentagon model as the conceptual framework. As seen in Figure 1, the model stresses the necessity of integrating entities, resulting in the composition among the PCK components. In the pentagon model, PCK studies comprise and examine knowledge of teacher trainees, comprehension, orientations to science teaching, knowledge of instructional techniques for science teaching, knowledge of assessing science learning, and knowledge of evaluation of components in scientific learning. This evenly weighted integration of all components ensures a high level of consistency (Park $\&$ Chen, 2012). The knowledge of curriculum as a component of PCK is dominating the existing curriculum of instructors and making the required adjustments and recommendations in this regard (Falk, 2012); this displays the teacher's abilities in terms of curriculum content (Park \& Steve-Oliver, 2008a). The elements of science education assessment highlights learners' progress using a technique that incorporates suitable measurement instruments, activities, and procedures that are aligned with the current curriculum (Park \& Oliver, 2008b). Tutors must have good skills, content knowledge, and knowledge of trainees' attitudes to assist these teacher trainees to develop the basic components of PCK (Jan et al., 2002). When broken down into its constituent parts, good teaching practices eliminate misconceptions regarding concepts. Learning loops, conceptual transformation tactics, and the inquiry-based technique as a whole are all examples of science teaching approaches (Park \& Oliver, 2008b). Instructional strategies are included in the science orientation information. For science education and PCK, beliefs about the origin of science and faith are components that cannot be separated from subject content knowledge (Jan et al., 2002).

\section{METHODOLOGY}

\section{Research Design}

The study design adopted is a descriptive survey. A descriptive survey design was employed to accurately obtain the detailed PCK characteristics of tutors and teacher trainees of colleges of education. A descriptive survey also provided a quantitative or numeric description of trends, attitudes, or opinions of the tutors and their teacher trainees used for the study (Avoke, 2001). It also gave people the chance to learn more about the situations or relations, the practices that are in place, the opinions, viewpoints, or attitudes that are held, the procedures that are taking place, the actions that are being taken, or the patterns that are developing (Cohen et al., 2017).

\section{Population and Sample}

The population of the study consists of all the 46 colleges of education in Ghana and the accessible population is comprised of two Colleges of Education in the Upper East and Upper West Regions of Ghana. Simple random sampling was employed to select 60 science teacher trainees from each of the two colleges. The breakdown being, forty-four (44) second-year teacher-teacher trainees in each college and 


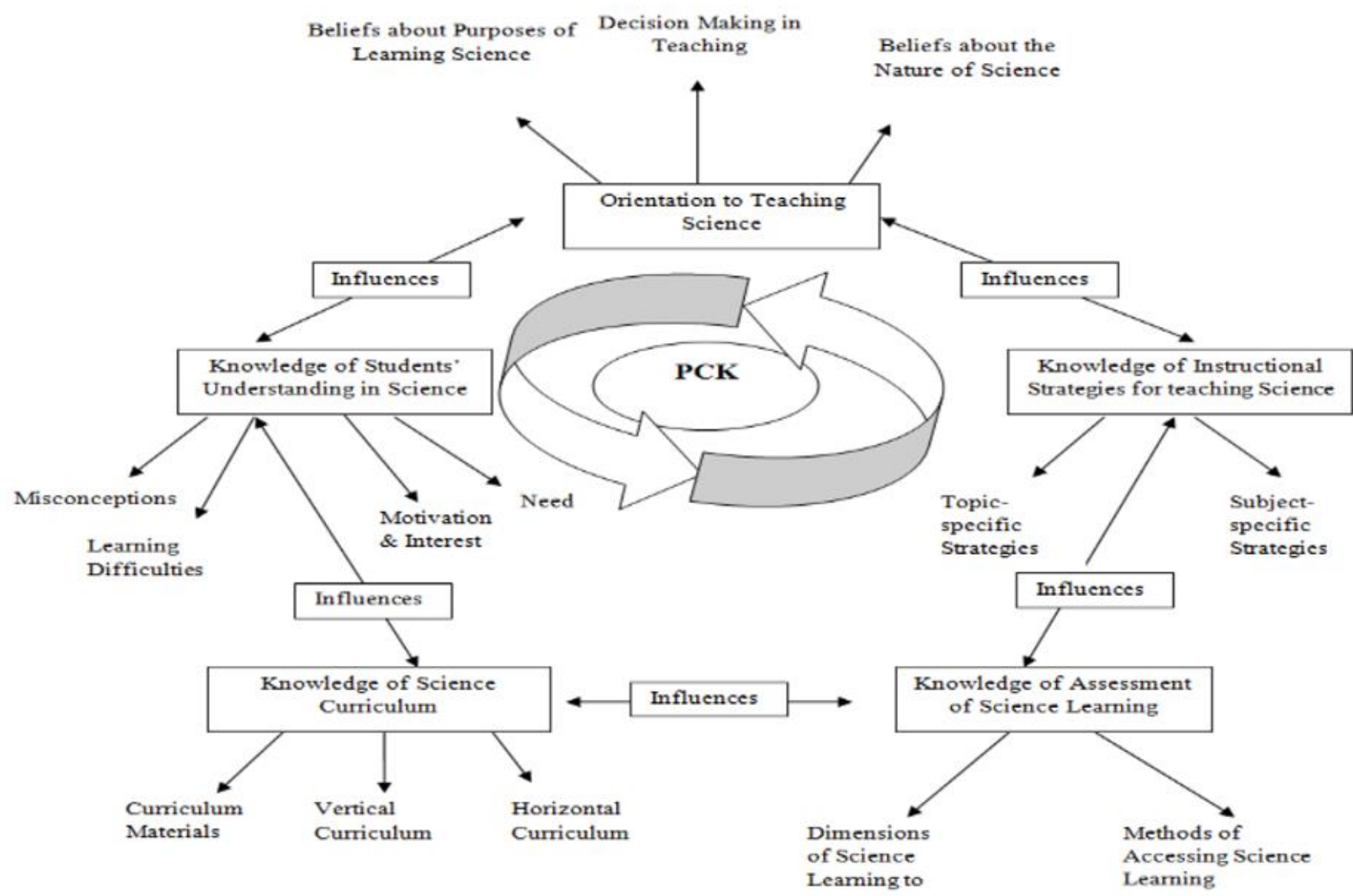

Figure 1. Pentagon model of PCK for teaching science (Alkis-Kucukaydin \& Ulucinar Sagir, 2016; Park \& Chen, 2012)

16 third-year teacher trainees from each college who were doing their off-campus teaching practice were sampled. Out of the 120 teacher trainees sampled, 98 were males and 22 were females. These teacher trainees are students who are under preparation and training to become professional teachers and they can also be referred to as pre-service teachers at a college or university. Purposeful sampling depending on the number of years of teaching experience and tutor's qualification and seen as information-rich- cases to the study was used to select three science tutors who were teaching biology, chemistry, and physics from each college and totaled six male science tutors.

\section{Research Instruments}

The main research instruments used for the study were a questionnaire, observation checklist, and interview guide.

\section{Questionnaire for teacher trainees assessing PCK exhibited by their tutors}

The construction of a questionnaire necessitates extensive testing to ensure its reliability and validity. Due to time and financial restrictions, existing questionnaires were adapted to better match the purpose of this study. A 36-item questionnaire adapted from that of Asplin and Marks (2013) was used for the survey to elicit responses from the teacher trainees about the extent of PCK exhibited by their science tutors and its influence on their PC K development.

\section{Observation checklist on tutors}

An observation schedule was also used in this study because it brings the investigator into contact with the phenomenon being studied (Sufian, 2015). An observation checklist was adopted from that of the Department of Science and Mathematics Education, C. K. Tedam University of Technology and Applied Sciences on- and off-campus teaching practice observation checklist to cross-check the items asked in the questionnaire on science tutors' PCK and its influence on the PCK development of the teacher trainees.

\section{Interview guide for tutors and their teacher trainees}

An interview guide was used to probe into some information provided on the questionnaire and the checklist as well as get some information or explanation which cannot be obtained when the questionnaire is solely relied on.

The interview provides more flexibility and also certain confidential information the interviewer might not have put in writing using the questionnaire (Sufian, 2015). Thus, the interview guide created room for the interviewer to have gathered vital but unanticipated information from participants to enrich the questionnaire data.

The interview guide consisted of three items each of which was mostly open-ended questions to ensure that respondents express themselves to give detailed information for the study. The interview guide was developed based on science tutors' understanding of the PCK and its importance in teaching science. The interview guide was scrutinized by experts to ensure content coverage.

The interview lasted for 20 hours; 10 minutes for each respondent, eight minutes to respond to the questions and two minutes to sum up. 
Table 1. Demographic characteristics of respondents, science tutors' educational qualification, and teaching experience

\begin{tabular}{|c|c|c|c|c|c|c|c|c|}
\hline \multirow{2}{*}{$\begin{array}{l}\text { College of } \\
\text { Education }\end{array}$} & \multirow{2}{*}{$\begin{array}{c}\text { Number of } \\
\text { science tutors }\end{array}$} & \multicolumn{2}{|c|}{ Educational qualification of science tutors } & \multicolumn{4}{|c|}{ Teaching experience of science tutors } & \multirow{2}{*}{$\begin{array}{c}\text { Number of } \\
\text { teacher trainees }\end{array}$} \\
\hline & & First degree & Second degree & Less than a year & 1-5 years & 6-10 years & Above 11 years & \\
\hline CoE 1 & $3(\mathrm{~A}, \mathrm{~B}$, and $\mathrm{C})$ & 1 & 2 & 0 & 1 & 2 & 0 & 60 \\
\hline CoE 2 & $3(\mathrm{X}, \mathrm{Y}$, and $\mathrm{Z})$ & 0 & 3 & 0 & 0 & 2 & 1 & 60 \\
\hline
\end{tabular}

\section{Validity and Reliability of the Instruments}

To ensure content and construct validity, the scales were examined by three instructional PCK experts in the Department of Science and Mathematics Education, C. K. Tedam University of Technology and Applied Sciences. Their opinions were sincerely considered to standardise the content validity of the instruments to cover the entire research area. The Cronbach's $\alpha$ reliability test was used to determine the internal consistency of the items in the questionnaire after a pilot study had been conducted in a sister college outside the study areas. The Cronbach's $\alpha$ coefficient for the piloted questionnaire was 0.79 , and the final questionnaire used for the study was 0.83 . According to Haji et al. (2017), an $\alpha$-value of 0.90 is considered exceptional, 0.80 is considered very good, and 0.70 is considered adequate. Hence, the reliability coefficient of the questionnaire items is statistically accepted as considerably high.

\section{Data Collection Procedure}

All the respondents of the study were anonymous. This was done to assure that the responses of the teacher trainees would notbe disclosed to their science tutors and that their grades would also not be affected. Teacher trainees' questionnaire was administered personally to respondents from the two colleges $(n=20)$ during academic hours to elicit responses from the teacher trainees about the extent of PCK exhibited by their science tutors and its influence on their PCK development. The questionnaire was collected back after the students had finished answering the questions. This was done to ensure a hundred percent return. After administering the questionnaire, the scheduled class lesson was carried out to observe the tutors using the observation checklist as a guide to cross-check the questions asked in the questionnaire on tutors' PCK and its influence on the PCK development of the teacher trainees. The interview followed immediately after the observation to probe into some information provided on the questionnaire and the checklist to gather the information that was not put in writing in the questionnaire and the checklist using the questionnaire or the checklist.

\section{Data Analysis Procedure}

Pearson product-moment correlation was utilized to find the strength of the relationship between science tutors' PCK and its influence on student teachers' PCK development. The retrieved teacher trainees' questionnaire was serially numbered, coded, and scored. The Statistical Package for the Social Sciences (SPSS version 16.0) was employed to analyze the data descriptively (using tables, graphs, frequencies, and percentages). All correlations were examined at the 0.01 significance level.

The observation data was analyzed by comparing and contrasting what was contained in the checklist against what the tutors actually exhibited in class by way of pedagogical skills. Notes were then made to reflect the reality of the teaching and learning situation. In the case of the interviews, they were first of all transcribed verbatim after the audios had been played. The line-by-line coding technique was subsequently utilized to code the transcripts and then categories were

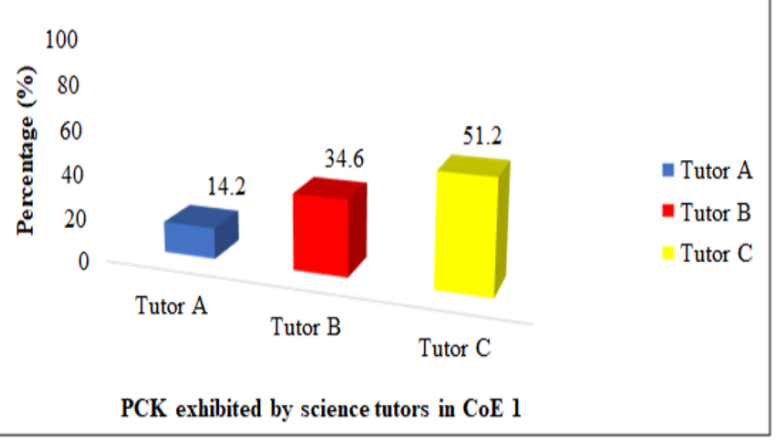

Figure 2. The extent of PCK exhibited by science tutors in $\operatorname{CoE} 1$

later developed after coding process. The final stage was development of themes from categories. These themes were then pieced together to provide basis for triangulation and further discussions.

\section{RESULTS AND DISCUSSION}

\section{Demographic Characteristics of Respondents}

The study used two colleges of education (CoE) in Upper East and Upper West Regions to obtain the data to answer the research objectives. These colleges of education under study were named CoE 1 and $\mathrm{CoE} 2$, respectively. The respondents from each college, science tutors' educational qualification, and teaching experience are presented in Table 1. All the six science tutors were males since there were no female science tutors in both the colleges at the time the study was conducted. Out of the 60 teacher trainees used for the study, 44 from each college were in second-year representing $73.3 \%$ while the rest of the 16 teacher trainees from each college were in their third-year and undertaking their out programme (off-campus teaching practice) representing $26.7 \%$. With the total of 120 teacher trainees sampled from the two colleges, $81.7 \%$ and $18.3 \%$ were males and females, respectively. The small number of female respondents is because the teacher trainees that were females in the two colleges of education under study were few.

Furthermore, out of the six science tutors sampled, five tutors, two (B and $\mathrm{C}$ ) at $\mathrm{CoE} 1$ and all the three $(\mathrm{X}, \mathrm{Y}$, and $\mathrm{Z}$ ) at $\mathrm{CoE} 2$, respectively have second degrees while one tutor $(\mathrm{A})$ in $\mathrm{CoE} 1$ has first degree only. Also, two tutors in each college, for instance, tutor $B$ and tutor $C$ as well as tutor $\mathrm{Y}$ and tutor $\mathrm{Z}$ in $\mathrm{CoE} 1$ and $\mathrm{CoE} 2$, respectively have 6-10 years of teaching experience while tutor $\mathrm{X}$ and tutor $\mathrm{A}$ in CoEs 2 and 1 have over 11 and 1-5 years of teaching experience, respectively.

What PCK Was Exhibited by Science Tutors of the Colleges of Education?

The data obtained from the questionnaire, interview guide, and observation checklist were triangulated to describe the extent of PCK exhibited by science tutors of the colleges of education. The results presented in Figure 2 and Figure 3 depict the extent of PCK exhibited by science tutors in the two colleges of education, $\operatorname{CoE} 1$ and $\operatorname{CoE} 2$, respectively. 


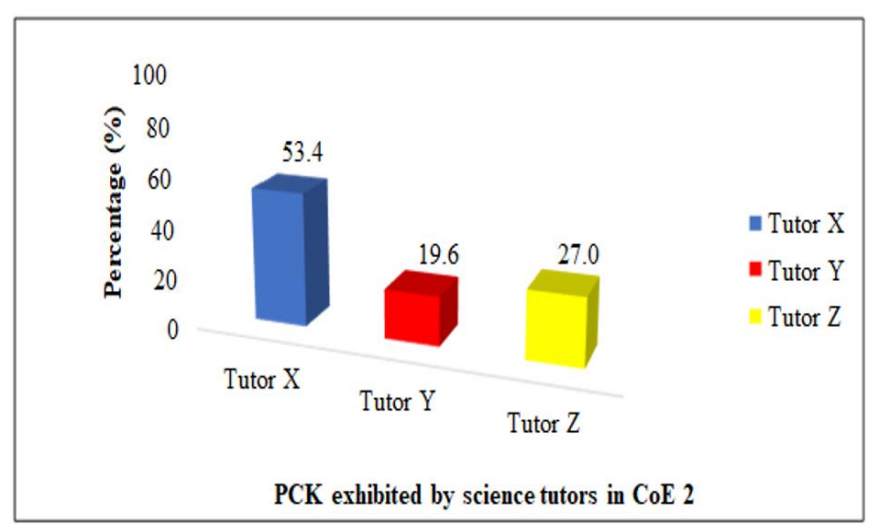

Figure 3. The extent of PCK exhibited by science tutors in CoE 2

Out of the six science tutors observed in both colleges, tutor $\mathrm{X}$ and tutor $\mathrm{C}$ in CoEs 2 and 1 demonstrated the highest PCK representing $53.4 \%$ and $51.2 \%$, respectively.

The PCK components were scored over $75 \%$ and out of this, tutor $\mathrm{X}$ and tutor C scored $53.4 \%$ and $51.2 \%$, respectively. The PCK components exhibited by tutor $\mathrm{X}$ include orientations toward science teaching (15.0\%), knowledge of students' understanding in science (10.0\%), knowledge of instructional strategies and representations (10.0\%), knowledge of assessment in science (10.0\%), and knowledge of curriculum (8.4\%). Also, the PCK components demonstrated by tutor C were knowledge of instructional strategies and representations (12.0\%), orientations toward science teaching (10.0\%), knowledge of assessment in science $(10.0 \%)$, knowledge of students' understanding of science (10\%) and knowledge of curriculum (9.2\%).

However, tutor B and tutor $\mathrm{Z}$ in CoEs 1 and 2 demonstrated only four PCK components representing $34.6 \%$ and $27.0 \%$, respectively. Both tutors in the two CoEs did not possess knowledge of the curriculum $(0.0 \%)$ as a PCK component. The PCK components exhibited by tutor B include knowledge of instructional strategies and representations (10.0\%), orientations toward science teaching (8.5\%), knowledge of students' understanding of science (8.1\%), and knowledge of assessment in science (8.0\%). Also, the PCK components exhibited by tutor $\mathrm{Z}$ were knowledge of instructional strategies and representations $(8.5 .0 \%)$, orientations toward science teaching $(7.0 \%)$, knowledge of assessment in science (6.0\%), and knowledge of students' understanding of science (5.5\%).

More so, out of the five PCK components, tutor $\mathrm{Y}$ and tutor A in CoEs 1 and 2 exhibited three PCK components representing 19.6\% and $14.2 \%$, respectively. However, both tutors in the two CoEs did not possess two of the PCK components. Tutor $\mathrm{Y}$ in CoE 1 did not possess knowledge of students' understanding of science $(0.0 \%)$ and knowledge of curriculum (0.0\%) as PCK components. Besides, tutor A in CoE 2 did not possess knowledge of curriculum $(0.0 \%)$ and assessment in science (0.0\%) as part of his PCK characteristics. The three PCK components demonstrated by tutor $\mathrm{Y}$ were orientations toward science teaching (7.5\%), knowledge of instructional strategies and representations (6.1\%), and knowledge of assessment in science (6.0\%). While the three PCK components demonstrated by tutor A were orientations toward science teaching (5.0\%), knowledge of instructional strategies and representations (5.0\%), and knowledge of students' understanding of science $(4.2 \%)$.

Comparatively, the study has shown that tutor $\mathrm{B}$ in $\mathrm{CoE} 1$ demonstrated higher PCK than that of tutor $\mathrm{Z}$ in $\mathrm{CoE} 2$ with $34.6 \%$ and

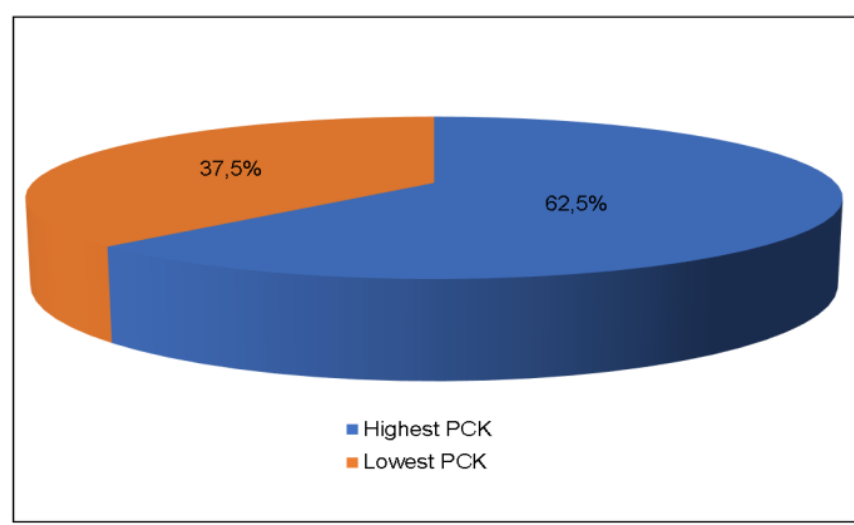

Figure 4. PCK development of teacher trainees in $\mathrm{CoE} 1$

$27.0 \%$, respectively even though both have second degrees in science education with 6 years of teaching experience. Furthermore, tutor Y and tutor A in CoE 2 and CoE 1 have the lowest PCK of $19.6 \%$ and $14.2 \%$, respectively with each having 5 years of teaching experience.

Also, the highest PCK demonstrated by tutor $\mathrm{X}$ and tutor $\mathrm{C}$ in CoEs 2 and 1 , respectively during the teaching and learning process may be due to several factors. For instance, tutor $\mathrm{X}$ in $\mathrm{CoE} 2$ has been teaching for the past 12 years while tutor $\mathrm{C}$ in $\mathrm{CoE} 1$ has been teaching for the past 10 years. According to van Driel et al. (2014), knowledge in a certain topic combined with teaching experience contributes positively to PCK development in science teachers. Furthermore, the study also found that both the science tutors who exhibited the highest PCK have second degrees in science education and so had prior knowledge about students' misconceptions and difficulties and how to address them. To make the subject matter more understandable to the students, the tutors use instructional tactics such as drawings, analogies, clarifications, and demonstrations. The science tutors' PCK provides a pathway for a deeper comprehension of the intricate relationship between a subject's content and its teaching by employing specialized teaching and evaluation methodologies (Nilsson \& Loughran, 2012).

This studyand many other studies have demonstrated that pedagogical content knowledge is very particular to each teacher, concepts being taught and is much more than merely subject matter knowledge and that it grows through time due to teaching experience. During the teaching process, each tutor's PCK is unique in that it demands tutors to transform their subject content knowledge for teaching purposes (Azam, 2020; Shulman, 1986).

Generally, the PCK demonstrated by two science tutors, X and C, were averagely good with a percentage score above $50.0 \%$. The highest PCK exhibited by tutor X and tutor C in CoEs 2 and 1, respectively could be due to their number of years of teaching experience and qualification. The PCK demonstrated by tutor Y in CoE 2 was similar to that of tutor A in CoE 1 and both exhibited the lowest PCK.

To What Extent Does the Pck of Science Tutors of Colleges of Education Influence the Pck Development of Their Teacher Trainees?

This question sought to investigate the extent to which the teacher trainees' PCK development is influenced by the PCK of their science tutors.

Figure 4 and Figure 5 presented below showed how the PCK of science tutors of colleges of education influence the PCK development of their teacher trainees. 


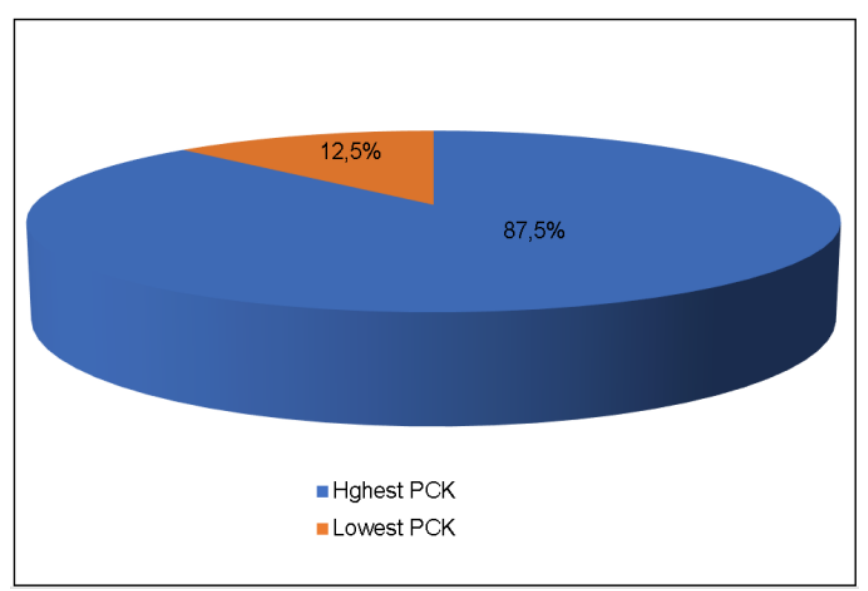

Figure 5. PCK development of teacher trainees in $\mathrm{CoE} 2$

The results in Figure 3 and Figure 4 indicated that out of the eight teacher trainees that were observed during their off-campus teaching practice, five and seven teacher trainees in CoEs 1 and 2 demonstrated the highest PCK representing $62.5 \%$ and $87.5 \%$, respectively.

The highest PCK exhibited by teacher trainees of CoEs 1 and 2 suggested that they adopted their tutor's style of teaching, especially tutors who exhibited the highest PCK in both colleges. In a study, Duschl et al. (2007) found a link between teachers' PCK and student science learning, indicating that PCK is an essential aspect of a teacher's level of understanding. The study also revealed that four teacher trainees, three in CoE 1 and one in $\mathrm{CoE} 2$ exhibited the lowest PCK representing $37.5 \%$. and $12.5 \%$, respectively. This could be attributed to the inability of novice teacher trainees to transform the content knowledge and teaching strategies acquired from their tutors into classroom practice.

Teaching and learning in primary science classrooms frequently focus on recitation and subject coverage, and teachers, particularly prospective and inexperienced teachers, sometimes have insufficient PCK. As a result, when teaching science, such teachers are terrified of unforeseen issues (Zembal-Saul et al., 2002). Kind (2009) recognized teacher trainees' lack of confidence in their content knowledge, as well as their awareness of students' challenges and how to make abstract ideas accessible to all students, as crucial parts of their early efforts at teaching. According to Kind and Wallace (1970), some science teacher trainees believe they know enough about their specialty and struggle to sort out the concepts needed to teach effectively. This could indicate that these prospective teacher trainees have not yet applied their science knowledge and understanding during instruction.

Is There a Relationship Between Science Tutors' Pck and the Pck of Their Student Teachers?

This question sought to determine if there is a linear relationship between the PCK of science tutors and the PCK of their student teachers (teacher trainees).

The Pearson's product-moment correlation was utilized to establish the linear relationship between student teachers' PCK and the PCK of their science tutors as presented in Table 2. The Pearson's productmoment correlation was used to analyze and test the data acquired from the research question at the 0.01 level of significance (2-tailed) and $\mathrm{N}=6$.

The results in Table 2 showed that the sig. (2-tailed) is 0.000 which is less than 0.01 for all science tutors in both colleges. This implies that the correlation is significant at the 0.01 alpha level. Hence, the results
Table 2. Pearson product-moment correlations on the relationship between science tutors PCK and the PCK of their teacher trainees

\begin{tabular}{lcc}
\hline College of education & $\begin{array}{c}\text { Pearson product- } \\
\text { moment correlation }\end{array}$ & Significance \\
\hline CoE 1 & 0.859 & 0.000 \\
\hline CoE 2 & 0.943 & 0.000 \\
\hline
\end{tabular}

indicated that there is a relationship between science tutors' PCK and that of the PCK of their teacher trainees with Pearson's productmoment correlation coefficient (r) of 0.859 and 0.943 for all tutors in CoEs 1 and 2, respectively. However, there is a very strong positive linear association between science tutors' PCK and the PCK development of their teacher trainees in $\mathrm{CoE} 2$ in comparison with $\mathrm{CoE}$ 1 due to the correlation coefficient $(r)$ value (0.943) which is closer to 1.00. According to Chee (2018), Pearson's $r$ is a easy approach to analyze the link between two factors, and the higher the level to which they are correlated, the more favorable the relationship is.

\section{CONCLUSIONS AND RECOMMENDATIONS}

All in all, instead of concluding, science teacher education might gain from more proactively incorporating PCK, that is, assisting beginning and inexperienced teachers in understanding the meaning of PCK and how being abreast of PCK may help them develop and enhance their practice.

The study indicated that science tutors with several years of teaching experience demonstrated higher PCK than tutors with few years of teaching experience. It was also revealed from the study that teacher trainees who adopted their tutor's ways of doing things in the classroom exhibited the higher PCK. Besides, the study also indicated that there is a relationship between science tutors' PCK and that of the PCK of their teacher trainees with Pearson's product-moment correlation coefficient (r) almost close to one (0.859-0.943).

The following recommendations have been made from the findings of the present study. First, there should be an agreement of adopting PCK model that is transformational, for preliminary training whereby in-service teachers are learning how to effectively teach new topics and subjects as well as teacher trainees starting out as teachers, leading to a mechanism of changing classroom practices. Second, science education curriculum should explicitly state what PCK entails by offering academic programmes as a form of explaining the current classroom practices and utilizing the accomplished core courses as model materials. Third, the emotional aspects of in-service and pre-service science teachers must be taken into consideration. This will assist the aspiring science teachers in accepting the truth that training to be a qualify science teacher is above just acquiring a very good degree or having a high qualification in science.

Author contributions: All authors were involved in concept, design, collection of data, interpretation, writing, and critically revising the article. All authors approve final version of the article.

Funding: The authors received no financial support for the research and/or authorship of this article.

Acknowledgements: The authors would like to thank to the principals of the colleges of education and all respondents who participated in the study. Declaration of interest: Authors declare no competing interest.

Data availability: Data generated or analysed during this study are available from the authors on request. 


\section{REFERENCES}

Adi Putra, M. J., Widodo, A., \& Sopandi, W. (2017). Science teachers' pedagogical content knowledge and integrated approach. Journal of Physics: Conference Series, 895, 012144. https://doi.org/10.1088/ $1742-6596 / 895 / 1 / 012144$

Alkis-Kucukaydin, M., \& Ulucinar Sagir, S. (2016). An investigation of primary school teachers' PCK towards science subjects using an inquiry-based approach. International Electronic Journal of Elementary Education, 9(1), 87-108.

Asplin, K. N., \& Marks, M. J. (2013). Increasing the influence of university supervisors during student teaching. The Professional Educator, 37(1), 1-10.

Avoke, M. (2001). Some historical perspectives in the development of special education in Ghana. European Journal of Special Needs Education, 16(1), 29-40. https://doi.org/10.1080/088562501505017 89

Azam, S. (2020). Locating personal pedagogical content knowledge of science teachers within stories of teaching force and motion. EURASIA Journal of Mathematics, Science and Technology Education, 16(12), 1-20. https://doi.org/10.29333/ejmste/8941

Bayram-Jacobs, D., Henze, I., Evagorou, M., Shwartz, Y., Aschim, E. L., Alcaraz-Dominguez, S., Barajas, M., \& Dagan, E. (2019). Science teachers' pedagogical content knowledge development during enactment of socioscientific curriculum materials. Journal of Research in Science Teaching, 56(9), 1207-1233. https://doi.org/ 10.1002/tea. 21550

Chee, J. D. (2018). Pearson's product-moment correlation: Sample analysis. University of Hawaii at Mãnoa School of Nursing.

Cohen, L., Manion, L., \& Morrison, K. (2017). Research methods in education. Routledge. https://doi.org/10.4324/9781315456539

Duschl, R., Schweingruber, H., \& Shouse, A. (2008). Taking science to school: Learning and teaching science in grades $K-8$. National Academies Press. https://doi.org/10.5860/choice.45-3327

Etkina, E. (2010). Pedagogical content knowledge and preparation of high school physics teachers. Physical Review Special Topics - Physics Education Research, 6(2), 120-131. https://doi.org/10.1103/ PhysRevSTPER.6.020110

Falk, A. (2012). Teachers learning from professional development in elementary science: Reciprocal relations between formative assessment and pedagogical content knowledge. Science Education, 96(2), 265-290. https://doi.org/10.1002/sce.20473

Goes, L. F., Fernandez, C., Eilks, I., \& Education, C. T. (2020). The development of pedagogical content knowledge about teaching redox reactions in German chemistry teacher education. Education Sciences, 10(7), 1-22. https://doi.org/10.3390/educsci10070170

Haji, S. A., Moluayonge, G. E., \& Park, I. (2017). Teachers' use of information and communications technology in education: Cameroon secondary schools perspectives. Turkish Online Journal of Educational Technology, 16(3), 147-153.

Jan, H. V. D., Onno De, J., \& Nico, V. (2002). The development of preservice chemistry teachers' pedagogical content knowledge. Science Education, 86(4), 572-590.https://doi.org/10.1002/sce.10010
Kind, V. (2009). Pedagogical content knowledge in science education: Perspectives and potential for progress. Studies in Science Education, 45(2), 169-204. https://doi.org/10.1080/03057260903142285

Kind, V., \& Wallace, R. (1970). Train, teach; taught? How the content of specific science subject matter knowledge sessions impacts on trainee teachers' classroom practice and children's learning. Nordic Studies in Science Education, 4(2), 151-167. https://doi.org/10.5617/ nordina. 290

Melo, L., Cañada-Cañada, F., González-Gómez, D., \& Jeong, J. S. (2020). Exploring pedagogical content knowledge (PCK) of physics teachers in a colombian secondary school. Education Sciences, 10(12), 1-15. https://doi.org/10.3390/educsci10120362

Nilsson, P., \& Loughran, J. (2012). Exploring the development of preservice science elementary teachers' pedagogical content knowledge. Journal of Science Teacher Education, 23(7), 699-721. https://doi.org/10.1007/s10972-011-9239-y

Park, S., \& Chen, Y. C. (2012). Mapping out the integration of the components of pedagogical content knowledge (PCK): Examples from high school biology classrooms. Journal of Research in Science Teaching, 49(7), 922-941. https://doi.org/10.1002/tea.21022

Park, S., \& Oliver, J. S. (2008). Revisiting the conceptualisation of pedagogical content knowledge (PCK): PCK as a conceptual tool to understand teachers as professionals. Research in Science Education, 38(3), 261-284. https://doi.org/10.1007/s11165-007-9049-6

Park, S., \& Steve Oliver, J. (2008). National board certification (NBC) as a catalyst for teachers' learning about teaching: The effects of the NBC process on candidate teachers' PCK development. Journal of Research in Science Teaching, 45(7), 812-834. https://doi.org/10.1002 /tea.20234

Shulman, L. S. (1986). Those who understand: Knowledge growth in teaching. Educational Researcher, 15(2), 4-14. https://doi.org/10. 3102/0013189X015002004

Skedsmo, G. (2020). Assessment and evaluation with clarifying purposes for policy and practice. Educational Assessment, Evaluation and Accountability, 32(2), 103-106. https://doi.org/10.1007/s11092020-09323-x

Sothayapetch, P., Lavonen, J., \& Juuti, K. (2013). Primary school teachers' interviews regarding pedagogical content knowledge (PCK) and general pedagogical knowledge (GPK). European Journal of Science and Mathematics Education, 1(2), 84-105. https://doi.org/ $10.30935 /$ scimath $/ 9390$

Sperandeo-Mineo, R. M., Fazio, C., \& Tarantino, G. (2006). Pedagogical content knowledge development and pre-service physics teacher education: A case study. Research in Science Education, 36(3), 235-268. https://doi.org/10.1007/s11165-0059004-3

Sufian, A. J. M. (2015). Methods and techniques of social research. International Journal of Business and Statistical Analysis, 2(2). https://doi.org/10.12785/ijbsa/020204

Thompson, J. R., Christensen, W. M., \& Wittmann, M. C. (2011). Preparing future teachers to anticipate student difficulties in physics in a graduate-level course in physics, pedagogy, and education research. Physical Review Special Topics - Physics Education Research, 7(1), 101-108. https://doi.org/10.1103/PhysRevSTPER.7. 010108 
Tobin, K., Briscoe, C., \& Holman, J. R. (1990). Overcoming constraints to effective elementary science teaching. Science Education, 74(4), 409-420. https://doi.org/10.1002/sce.3730740402

van Driel, J. H., Berry, A., \& Meirink, J. (2014). Research on science teacher knowledge. In S. Abell, \& N. Lederman (Eds.), Handbook of research on science education. Routledge.
Williams, P. (2003). A passion for learning begins with a spark: Message from the president. ASCD. https://www.ascd.org/el/articles/apassion-for-learning-begins-with-a-spark

Zembal-Saul, C., Krajcik, J., \& Blumenfeld, P. (2002). Elementary student teachers' science content representation. Ournal of Research in Science Teaching, 39, 443-463. https://doi.org/10.1002/tea.10032 